\title{
THE RESULTS OF TREATMENT OF MALLET FINGER
}

\author{
W. A. T. Robb, Edinburgh, Scotland \\ Senior Registrar, Royal Infirmary of Edinburgh
}

Mallet finger is the deformity caused by a tear of the extensor expansion from its attachment to the base of the terminal phalanx. Sometimes there is an associated fracture caused by avulsion of a small triangular fragment of bone. The terminal phalanx is flexed and the power of active extension is lost, and there may be a secondary hyperextension of the proximal interphalangeal joint due to the exertion of the full power of the extensor mechanism of this joint.

The method of treatment generally recommended for a mallet finger, particularly if it is seen within a few days of injury, is immobilisation by a plaster splint in the position of hyperextension of the distal joint and flexion of the proximal joint for four to six weeks. The impression created is that the immediate results of this treatment are good (Smillie 1937, Watson-Jones 1940).

The present review was carried out to assess the long-term results of treatment, and in particular to determine whether or not freedom from disability and restoration of full movement were achieved.

\section{MATERIAL}

Seventy-five patients with mallet finger treated in the surgical out-patient department of the Royal Infirmary of Edinburgh during the years 1952, 1953 and 1954 were reviewed. The shortest time that had elapsed between the injury and the follow-up examination was one year.

\section{ETIOLOGY}

The highest incidence was found in the fifth and sixth decades, and men were affected more often than women. The ring and little fingers were injured in fifty cases, the middle and index fingers in twenty-four cases, and the thumb in only one case. These findings are in general agreement with other reported series (Mason 1930, Smillie 1937, Ratliff 1947).

Industrial injuries and accidents in the home, especially during bed-making, accounted for most cases. The alleged common cause-sports, such as cricket-was not encountered in this series.

In thirty of the seventy-five cases there was radiological evidence of a fracture at the time the patient was first seen.

\section{METHOD OF TREATMENT}

Sixty-nine patients were treated by immobilisation in plaster in the position of hyperextension of the distal interphalangeal joint and flexion of the proximal joint. An analysis of those cases, however, showed that in only thirty had a satisfactory plaster been maintained for at least four weeks. In the others a change of splint had been required because the plaster had become too tight, too loose, or had become soft through getting wet. Sometimes the plaster had come off and had not been replaced, usually because the patient had not reported to hospital.

Two patients had no treatment and four had operative repair of the ruptured tendon.

\section{RESULTS}

Subjective-Any complaints made by the patients were recorded and, in particular, each patient was specifically asked about discomfort or any interference with normal activities. 
One patient stated that persistent deformity and lack of power caused considerable inconvenience in the course of her ordinary household activities inasmuch as she constantly tended to knock her finger and " it caught on things." She had been treated by uninterrupted immobilisation of the finger in plaster for six weeks.

Five patients complained of occasional discomfort in the region of the terminal interphalangeal joint, especially during cold weather. One had severe constant pain from osteoarthritis in the joint.

The striking finding at the time of examination was the complete absence of symptomatic disability in all but the above. However, questioning elicited the fact that this freedom from trouble was not generally an immediate sequel to the end of treatment. The usual course was a slow improvement over several months from the time of injury.

Objective-The range of movement at a normal distal interphalangeal joint was found to show great individual variation. For this reason active and passive movement of the affected joint was compared with the corresponding joint of the opposite side and any limitation of flexion or extension was expressed as a percentage of the normal range for that individual patient (Table I).

TABLE

Range of Movement after Treatment (71 Cases)

\begin{tabular}{|c|c|c|}
\hline Active movement & Number of cases & Per cent \\
\hline Full range & 16 & $22 \cdot 5$ \\
\hline $75-100$ per cent & 47 & $66 \cdot 0$ \\
\hline 50-75 per cent. & 6 & $8 \cdot 5$ \\
\hline Less than 50 per cent & 2 & $3 \cdot 0$ \\
\hline
\end{tabular}

A perfect anatomical result was obtained in less than a quarter of the total, and a severe deformity was still present in approximately a tenth. Of the fifty-five patients with some restriction of active movement, twenty-eight ( 51 per cent) had a full range of passive movement.

In the analysis of the results of treatment the following factors were specifically noted.

Immobilisation-There was no significant difference between those cases in which uninterrupted immobilisation in hyperextension for at least four weeks had been carried out, and those in which immobilisation had been inefficient for the reasons described above. Indeed, many patients stated that after removal of a plaster which had been considered satisfactory the affected finger was stiff for a few days and then the mallet deformity recurred. Over a variable time thereafter the deformity slowly but steadily decreased until the final state of recovery was reached. No further improvement was ever noted after six months from the time of injury. This also proved true for those patients who had unsatisfactory splints and for the two individuals who had no treatment.

Early treatment-There was no difference in the ultimate outcome between patients who had treatment within three days of the injury and those in whom the start of the treatment had been delayed for up to three weeks.

Fracture-The presence of an associated fracture in thirty cases did not affect the incidence of persistent deformity, but did increase the liability to subjective complaints. Four of the five patients who complained of discomfort had sustained a fracture.

Operation-Of the four patients who had operative repair of the ruptured tendon one complained of discomfort. Only one had a perfect anatomical result: in the other three there was an average restriction of extension by 20 degrees and of flexion by 10 degrees at the distal interphalangeal joint.

vol. 41 B, NO. 3, AUGUST 1959 
Complications of treatment-Ten patients had pressure sores, eight of which were over the dorsal aspect of the distal interphalangeal joint, and the scarring associated with healing had caused some limitation of flexion. Since the completion of this follow-up, one patient has been seen in whom too tight a plaster had caused gangrene of the terminal phalanx, necessitating partial amputation of the finger.

\section{DISCUSSION}

The principle of treatment by hyperextension of a mallet finger is based on the fact that flexion of the proximal joint fixes the middle slip and allows the two lateral bands of the extensor aponeurosis to be approximated to the site of their distal attachment.

Many types of splint have been devised to maintain this position, but the most popular method is the application of a plaster. There are two problems associated with its use: 1) Application-The different techniques described by Smillie (1937), Bunnell (1944), Howie (1947). Williams (1947) and Watson-Jones (1956) indicate the difficulty of fitting an efficient plaster. 2) Maintenance - In this series less than half the patients were considered to have had a satisfactory plaster for the reasons already given. Any change of plaster during the period of immobilisation may allow flexion of the distal interphalangeal joint-even though it be momentary - and upsets the principle of treatment.

The present review indicates that the mechanical difficulties of plaster immobilisation of a mallet finger with flexion of the middle joint are considerable and thus confirms the observations of other writers (Rosenzweig 1950, Pratt 1952). It shows that on removal of the plaster the immediate results may be satisfactory but that in many cases the deformity recurs. Duncan (1948) noted that on removal of the plaster there was invariably a fully extended joint but that within forty-eight hours the flexion deformity recurred in approximately half of the patients treated. The poor early results of conservative treatment have caused some surgeons to carry out immediate operation. Pratt (1952) advised internal fixation of the joints of the fingers by a Kirschner wire to maintain the desired position for six weeks, and Mason (1930) recommended early operative repair of the ruptured extensor expansion.

The results of operative repair are not always satisfactory. The cosmetic effect may be good but the restoration of a full range of movement is uncommon. In fact, movement is often less than after conservative treatment: in particular, flexion of the distal interphalangeal joint may be restricted by scarring on the dorsal aspect, as was noted in three of our four patients who were treated by operation. Rosenzweig (1950) also considered that " the results of operative repair left a lot to be desired."

The assessment of the late results in this series suggests that early operative repair is unnecessary. Improvement occurs gradually as healing and contraction of fibrous tissue proceed, and, although lengthening of the tendon is responsible for a high incidence of incomplete extension, the subjective end results are good. This assessment is in agreement with that of Rosenzweig (1950), and suggests that a satisfactory state of recovery will occur in practically all cases of mallet finger even if no treatment is given. The finger may be strapped with adhesive strapping or a straight spatula splint may be applied to the palmar aspect of the fingers to relieve the initial discomfort associated with the injury. This form of treatment, which is easy to apply, comfortable for the patient and devoid of the risk of pressure sores, is now being used in this department.

\section{CONCLUSIONS}

1. The method of treatment of a mallet finger deformity by immobilisation in a plaster in the position of hyperextension of the distal interphalangeal joint and flexion of the proximal interphalangeal joint is, on the whole, unsatisfactory because the splint is difficult to apply, it may need to be changed frequently, and it is sometimes complicated by pressure sores.

2. In many cases the deformity is still present after six weeks of adequate immobilisation, but gradual improvement from the contraction of fibrous tissue occurs for up to six months. 
Therefore an assessment of the results of any method of treatment should be made only after an interval of at least six months.

3. The subjective end results at the end of six months are satisfactory whether or not there has been efficient immobilisation in hyperextension. Few patients have any disability and only rarely is this sufficient to cause interference with normal activities. A high proportion of patients show slight persistent deformity and limitation of movement, and this is seemingly uninfluenced appreciably by the type or duration of treatment.

4. The only treatment necessary for most cases of mallet finger is the application of elastic adhesive strapping or a straight spatula splint in order to relieve the initial discomfort from the injury.

\section{REFERENCES}

Bunnell, S. (1944): Surgery of the Hand. Philadelphia, London, Montreal: J. B. Lippincott Company. Duncan, J. McK. (1948): Trauma of the Hand. British Journal of Surgery, 35, 397.

Howie, H. (1947): The Treatment of Mallet Finger. A Modified Plaster Technique. New Zealand Medical Journal, 46, 513.

MASON, M. L. (1930): Rupture of Tendons of the Hand. Surgery, Gynecology and Obstetrics, 50, 611.

Pratt, D. R. (1952): Internal Splint for Closed and Open Treatment of Injuries of the Extensor Tendon at the Distal Joint of the Finger. Journal of Bone and Joint Surgery, 34-A, 785.

Ratliff, A. H. C. (1947): “ Mallet” Finger. A Review of 45 Cases. Manchester Medical School Gazette, 26, 4. Rosenzweig, N. (1950): Management of the Mallet Finger. South African Medical Journal, $24,831$.

Smillie, I. S. (1937): Mallet Finger. British Journal of Surgery, 24, 439.

Watson-Jones, R. (1940): Fractures and Other Bone and Joint Injuries. Edinburgh: E. \& S. Livingstone.

Watson-Jones, Sir R. (1956): Fractures and Joint Injuries. Fourth edition, Vol. 2, p. 645. Edinburgh and London: E. \& S. Livingstone Ltd.

Williams, E. G. (1947): Treatment of Mallet Finger. Canadian Medical Association Journal, 57, 582. 